\title{
Welcome to BMJ Evidence-Based Medicine
}

\section{Carl Heneghan, Editor in Chief, BMJ Evidence-Based Medicine}

10.1136/bmjebm-2018-110906

Centre for Evidence-Based

Medicine, University of

Oxford, UK

Correspondence to: Professor Carl Heneghan, Centre for Evidence-Based Medicine, University of Oxford, Oxford, UK; carlheneghan@bmj.com
Check for updates

To cite: Heneghan C. BMJ Evidence-Based Medicine 2018;23:45
This month we launch a new design for the journal, both in print and web, along with a change in our name-BMJ Evidence-Based Medicine-and the addition of new article types.

We have subtly changed our name, to build on the strengths of the $B M J$ s evidence-based mission. The $B M J$ and its associated publications have consistently published, promoted and campaigned for better evidence to inform decision making. Our publication on 10 essential papers for evidencebased medicine ${ }^{1}$ highlights a number of essential evidence-based medicine (EBM) articles in the $B M J$ : EBM: what it is and what it isn't, ${ }^{2}$ the scandal of poor medical research ${ }^{3}$ and assessing the quality of research, ${ }^{4}$ among others.

When the journal was first launched, the emerging clinical discipline of EBM aimed to bring the best evidence from clinical and healthcare research to the bedside, clinic or the community. Access to evidence was limited, the internet was emerging, and the journal was only available in print format

There is, however, still a need to find and summarise the evidence that matters. Much of what is currently produced is of poor quality, partially reported and often lacks essential outcomes that make a difference to care. ${ }^{5}$ Therefore, the revamped journal will focus on the tools, methods and concepts that are basic and central to practising EBM. We require a better understanding of the biases that permeate much of what is reported, better tools to interpret data and more debate around what can improve the skills of clinicians and the public when it comes to understanding health claims.

We are also partnering with the Evidence Live ${ }^{6}$ and Preventing Overdiagnosis ${ }^{7}$ conferences by publishing abstract books from the conference submissions, promoting campaigns such as the EBM Manifesto ${ }^{5}$ and becoming a home to the controversial topics that matter to health.

To do this, we have reorganised and renamed the types of article we publish under three themes: debate, analysis and opinion; original research; and our clinical spotlight section. The latter of these includes our BMJ EBM Spotlight blog, ${ }^{8}$ which takes a critical approach to interpreting evidence directly relevant to patient care decisions and actions. Blogs are written by our editors, by invite, and on occasion submitted to us. As editors, we believe in being critical, thoughtful and analytical in our approach to producing content

Early developments in EBM have focused on the internal validity of research evidence. The Evidence Manifesto, however, highlights there is much room for improvement. ${ }^{5}$ We need rigorous, robust, efficient research that matters, and importantly published in full. Dealing with uncertainty requires skills in assessing evidence and recognising poor-quality research.

Our focus won't stop with the education of medical professionals; it is also about educating the wider population of healthcare professionals and all those in the evidence ecosystem, including patients and the public. We will, therefore, deliver educational materials suitable for the public, for trainees and for practising professionals. What evidence affects clinical practice is a central question at the forefront of our thinking and journal's content. ${ }^{9}$ We source our commentaries from a large number of journals. Currently, most research is of unclear value or thought not to be practice-changing. We want to change this by publishing original evidence-based analysis, insights and opinions on what matters to healthcare.

Competing interests $\mathrm{CH}$ is Director of the Centre for Evidence-Based Medicine at the University of Oxford and jointly runs the Evidence Live and Preventing Overdiagnosis conferences with the $B M J$ and associated partners. Both conferences run on a not-for-profit basis.

Provenance and peer review Commissioned; internally peer reviewed.

๑ Article author(s) (or their employer(s) unless otherwise stated in the text of the article) 2018. All rights reserved. No commercial use is permitted unless otherwise expressly granted.

\section{References}

1. Nunan D, O'Sullivan J, Heneghan C, et al. Ten essential papers for the practice of evidence-based medicine. Evid Based Med 2017;22:202-4.

2. Sackett DL, Rosenberg WM, Gray JA, et al. Evidence based medicine: what it is and what it isn't. $B M J$ 1996;312:71-2.

3. Altman DG. The scandal of poor medical research. BMJ 1994;308:283-4.

4. Glasziou P, Vandenbroucke JP, Chalmers I. Assessing the quality of research. BMJ 2004;328:39-41.

5. Heneghan C, Mahtani KR, Goldacre B, et al. Evidence based medicine manifesto for better healthcare. $B M J$ 2017;357:j2973.

6. Evidence Live. http://evidencelive.org (accessed 16 Jan 2018)

7. https://www.preventingoverdiagnosis.net/ (accessed 16 Jan 2018).

8. http://blogs.bmj.com/bmjebmspotlight/ (accessed 16 Jan 2018).

9. Coombs C, Onakpoya I, Mahtani K, et al. What evidence affects clinical practice? An analysis of Evidence-Based Medicine commentaries. Evid Based Med 2017;22:197. 